\title{
Optical Properties of Copper (I) Oxide Thin Films Synthesized by SILAR Technique
}

\author{
Oluyamo, S.S, Nyagba, Mbafan .S*, Ojo, Ambrose . S. \\ Department of Physics, Federal University of Technology, P.M.B. 704, Akure, Ondo State Nigeria.
}

\begin{abstract}
In this research work, Copper(I)oxide $\left(\mathrm{Cu}_{2} \mathrm{O}\right)$ thin films were synthesized using Successive Ionic Layer Adsorption and Reaction (SILAR) technique. Fixed concentrations and temperature of two anionic precursors (1.0M at $70^{\circ} \mathrm{C}$ for $\mathrm{KOH}$ and $\mathrm{NaOH}$ ) and same cationic precursor (Copper Sulphate complex solution at room temperature) were used to obtain two set of films. Optical properties and applications of the films were examined. X-ray diffraction (XRD) analysis showed that both films are polycrystalline with a simple cubic structure. The absorbance, transmittance and reflectance of the material revealed $\mathrm{Cu}_{2} \mathrm{O}$ applicability as a Transparent Conducting Oxide (TCO). The energy band gaps obtained were 2.2 and $2.3 \mathrm{eV}$ for the different precursors. This indicates that the choice of precursor in this deposition technique has an effect on the energy band gap of the material.
\end{abstract}

Key words: SILAR, Optical properties, Anionic precursor, TCO, Energy band gap.

\section{Introduction}

The deposition and characterization of nano crystalline Copper(I) Oxide $\left(\mathrm{Cu}_{2} \mathrm{O}\right)$ thin films has attracted reasonable attention due to its numerous applications one of which is its ability to be used as a Transparent Conducting Oxide (TCO). TCOs are electrical conductive materials with comparably low absorption of electromagnetic waves within the visible region of the spectrum. They are usually prepared in the form of thin film and are used in opto-electrical devices such as solar cells, displays, opto-electrical interfaces and circuitries[1,2].

$\mathrm{Cu}_{2} \mathrm{O}$ is a $\mathrm{P}$ - type semiconductor with energy band gap values ranging from $2.0-2.6 \mathrm{eV}$ depending on its method of fabrication and stiochiometry. It is also reported to be brownish yellow in appearance with high transparency and absorbs light of wavelengths below $600 \mathrm{~nm}[3,4]$

Nano phase materials can be synthesized using different methods which can be classified into chemical processes, spray techniques and physical vapour deposition techniques[5]. Thin films of $\mathrm{Cu}_{2} \mathrm{O}$ have been deposited using the reactive sputtering methods, molecular beam epitaxy, chemical vapour deposition and reactive Rutherford magnetron sputtering etc.[6]. In this work, the process adopted is a modified chemical bath deposition technique known as Successive Ionic Layer Adsorption and Reaction (SILAR). Thin films are obtained from this technique by alternating the immersion of the substrate in an anionic, then cationic precursor solution. Between these immersions of the substrate in the precursors, the substrate is rinsed in distilled water. The SILAR method is mainly based on the adsorption and reaction of ions from the solutions while rinsing between every immersion with distilled water is to avoid homogeneous precipitation in the solution[7].

For the deposition of $\mathrm{Cu}_{2} \mathrm{O}$ thin films in this work, two anionic precursors $(\mathrm{NaOH}$ and $\mathrm{KOH})$ were used with the same cationic precursor (Copper complex solution) to obtain two set of films.

\subsection{Deposition process.}

\section{Experimental procedure.}

Pre-cleaned glass substrates (microscope slides of approximately 76 by 26 by $1 \mathrm{~mm}^{3}$ dimensions) were weighed, labelled and masked; exposing only the surface on which the material was to be deposited.In preparing the precursor solutions, the following chemicals were used: Copper Sulphate pentahydrate $\left(\mathrm{Cu}_{3} \mathrm{O}_{4} .5 \mathrm{H}_{2} \mathrm{O}\right)$, Sodium Thiosulphate $\left(\mathrm{Na}_{2} \mathrm{~S}_{2} \mathrm{O}_{3}\right)$, Sodium Hydroxide $(\mathrm{NaOH})$ and Potassium Hydroxide $(\mathrm{KOH})$. A molar solution of each of these chemicals was prepared and kept in a $250 \mathrm{ml}$ conical flask. The required Copper Thiosulphate complex solution was obtained ( $50 \mathrm{ml}$ in this case) by adding $25 \mathrm{ml}(125 \mathrm{ml})$ of $1 \mathrm{M} \mathrm{Na}_{2} \mathrm{~S}_{2} \mathrm{O}_{3}$ to 5 $\mathrm{ml}(25 \mathrm{ml})$ of the $1 \mathrm{M} \mathrm{Cu}_{3} \mathrm{O}_{4} .5 \mathrm{H}_{2} \mathrm{O}$, giving a colourless solution. The formation of the colourless solution can be represented by the equation:

$$
2 \mathrm{Cu}^{2+}+4 \mathrm{~S}_{2} \mathrm{O}_{2}^{3-} \Leftrightarrow 2\left[\mathrm{Cu}\left(\mathrm{S}_{2} \mathrm{O}_{3}\right)\right]^{-}+\left[\mathrm{S}_{4} \mathrm{O}_{6}\right]^{2-}
$$

$20 \mathrm{ml}$ of distilled water was then added to the mixture to obtain $50 \mathrm{ml}$ stock solution. $150 \mathrm{ml}$ of distilled water will be added if $250 \mathrm{ml}$ beaker is used.

About $50 \mathrm{ml}$ of the $\mathrm{NaOH}$ and $\mathrm{KOH}$ solutions was measured and poured into separate $50 \mathrm{ml}$ beakers. The solutions were heated up to $70^{\circ} \mathrm{C}$ and maintained at that temperature with the use of a regulated hot plate. 
Using the Copper Thiosulphate complex solution as the cationic precursor, the $\mathrm{KOH}$ and $\mathrm{NaOH}$ as the alternate anionic precursors, two sets of $\mathrm{Cu}_{2} \mathrm{O}$ thin films were deposited as follows:

For the case of $\mathrm{NaOH}$ as anionic precursor, the pre-labelled glass slide was immersed vertically in the heated $\mathrm{NaOH}$ solution and held there for 20 seconds. $\mathrm{OH}^{-}$from the solution adhered to the surface of the substrate. The substrate was taken out and immersed immediately into the Copper Thiosulphate complex solution and held there for another 20 seconds. In this solution (Thiosulphateocuprate (I)), the $\mathrm{Cu}(\mathrm{I})$ ions formed by dissociation equilibrium, adhered to the substrate and reacted with the Hydroxide ions $\left(\mathrm{OH}^{-}\right)$present on the surface to form $\mathrm{Cu}_{2} \mathrm{O}$. Equation 2 illustrates this process.

$$
2 \mathrm{Cu}^{+}+2 \mathrm{OH}^{-} \rightarrow \mathrm{Cu}_{2} \mathrm{O}+\mathrm{H}_{2} \mathrm{O}
$$

The slide was then removed and rinsed in a beaker of distilled water for about 5 seconds. With this, one cycle of the SILAR technique is complete. Successive cycles led to increase in thickness of the deposited film. The same process was repeated for another set of slides, only this time, the anionic precursor was changed to $\mathrm{KOH}$ and the rinsing step carried out after removal of the substrate from the anionic precursor was skipped. Three samples of $\mathrm{Cu}_{2} \mathrm{O}$ thin films deposited using $\mathrm{KOH}$ as anionic precursor were obtained. Films deposited after 30,40 and 50 cycles for each case, were analysed.

\subsection{Characterization.}

Structural analysis of the $\mathrm{Cu}_{2} \mathrm{O}$ samples was carried out in this research work with the use of an XPERT-PRO (PANanalytical BV, Netherlands) X-ray Diffraction (XRD) machine with scanning angles in the range 20-70 degrees using Cobalt radiation source $\left(\lambda=1.79 \mathrm{~A}^{\circ}\right)$.

The optical analysis was performed with the aid of a UV- visible spectrometer (Jenway- 6405 model).

\subsection{Film thickness.}

\section{Result and Discussions}

The thickness of the deposited films was gravimetrically determined and results obtained were 382.40 , $444.90,292.43 \mathrm{~nm}$ for films deposited with $\mathrm{KOH}$ as anionic precursor while those obtained from $\mathrm{NaOH}$ had a thickness of 1127.0, 2447.0, $5083.0 \mathrm{~nm}$ respectively. These varying thicknesses show that change in the anionic precursor from $\mathrm{KOH}$ to $\mathrm{NaOH}$ results to an increase in thickness of the film for same number of cycles in the SILAR process.

\subsection{Structural analysis.}

Figure 1 below show the XRD pattern of the analysed $\mathrm{Cu}_{2} \mathrm{O}$ thin films as obtained from $\mathrm{KOH}$ and $\mathrm{NaOH}$ Precursors with thickness 444.90nm and $2447.0 \mathrm{~nm}$ respectively for 40 cycles of the SILAR deposition process.

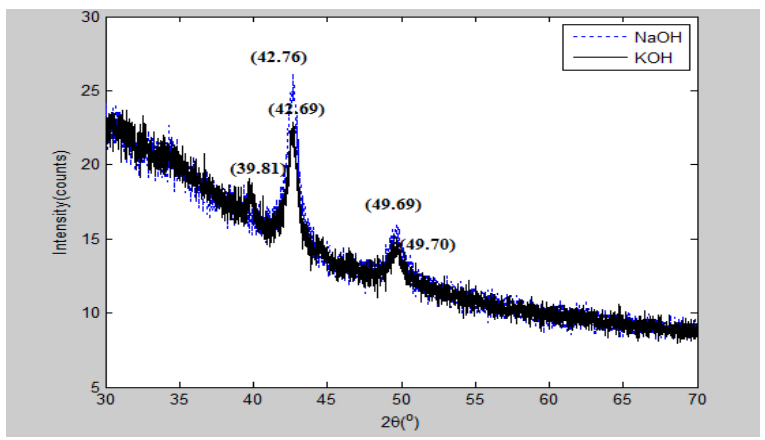

Figure 1: XRD pattern of $\mathrm{Cu}_{2} \mathrm{O}$ thin films deposited using $\mathrm{KOH}$ and $\mathrm{NaOH}$ precursors.

Figure 1 shows a pronounced peak at $42.76^{\circ}$ for the $\mathrm{NaOH}$ sample while the $\mathrm{KOH}$ sample has a pronounced peak at $42.69^{\circ}$. This diffraction pattern depicts the preferred orientation plane of the material as (111), (200) and (220) corresponding to the $2 \theta$ angles of $39.81^{\circ}, 42.69^{\circ}$ and $49.70^{\circ}$ for the $\mathrm{KOH}$ sample while that for the $\mathrm{NaOH}$ sample has orientation planes of (200) and (220) corresponding to the $2 \theta$ angles of $42.76^{\circ}$ and $49.69^{\circ}$. Both samples are polycrystalline with a simple cubic structure. These results are in agreement with the Joint Committee on Powder Diffraction Standards (JCPDS) data for $\mathrm{Cu}_{2} \mathrm{O}$. Card No. 41-025, $05-0667$ [8, 9] 


\subsection{Optical Analysis.}
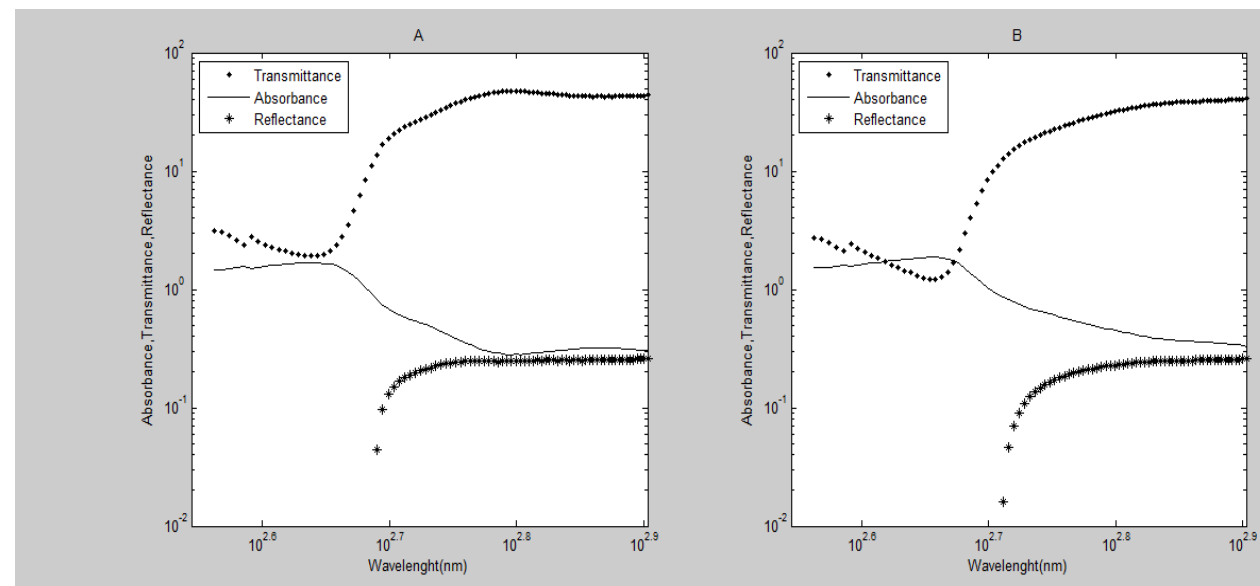

Figure 2. Transmittance, Absorbance and Reflectance of $\mathrm{Cu}_{2} \mathrm{O}$ thin film as deposited using $\mathrm{A}: \mathrm{NaOH}$ as anionic precursor/ B: KOH as anionic precursor in the SILAR technique.

Figure 2 shows the Absorbance, Transmittance and Reflectance of the $\mathrm{Cu}_{2} \mathrm{O}$ thin films. For both samples, as can be seen in figure 2, the Absorbance shows a little increase (wavelength range of $365-500 \mathrm{~nm}$ ) and then decreases with increase in wavelength of the electromagnetic spectrum. The transmittance for both samples increased gradually at wavelength approximately $465 \mathrm{~nm}$ until it reaches a plateau. This could be attributed to the fact that the sample seizes to absorb light above this wavelength. Hence, the material is transparent to light within the visible region of the electromagnetic spectrum thereby revealing its applicability as a Transparent Conducting Oxide. Its reflectance as depicted, is low.

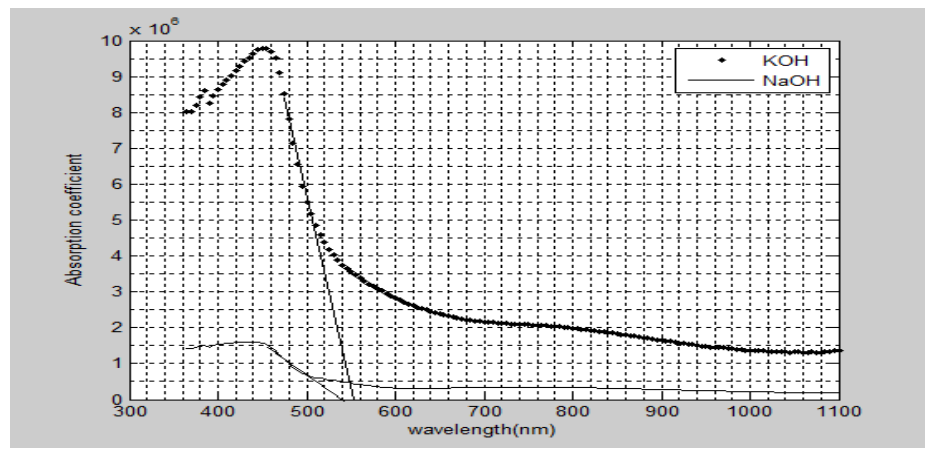

Figure 3. Absorption band edge of $\mathrm{Cu}_{2} \mathrm{O}$ samples as obtained from $\mathrm{KOH}$ and $\mathrm{NaOH}$ anionic precursors of the SILAR deposition process.

Figure 3 shows the absorption band edge of the two $\mathrm{Cu}_{2} \mathrm{O}$ samples. Their band gap energy was calculated from the relation

$$
E_{g}=h v=\frac{h c}{\lambda} .
$$

$v$ is the frequency, $\mathrm{h}$ is plank's constant and $\lambda$ is the cut off wavelength. This wavelength is obtained by extrapolation of a straight line from the absorption band edge to the point where the absorption coefficient is zero. From figure 3 , the cut off wavelengths are $~ 560 \mathrm{~nm}, 540 \mathrm{~nm}$ with corresponding band gap energies of 2.2 $\mathrm{eV}$ and $2.3 \mathrm{eV}$ for the $\mathrm{KOH}$ and $\mathrm{NaOH}$ samples respectively.

\section{Conclusion}

$\mathrm{Cu}_{2} \mathrm{O}$ thin films were deposited via the SILAR deposition technique. They were found to be polycrystalline with a simple cubic structure. Changing the anionic precursor had effects on the film thickness and energy band gap. Those obtained with $\mathrm{NaOH}$ as anionic precursor were thicker and had a higher energy band gap as compared to those obtained from the $\mathrm{KOH}$ anionic precursor. Both films were found to be transparent to light of wavelength within the visible region of the electromagnetic spectrum. 


\section{References}

[1]. Andreas,Stadler (2012). Transparent Conducting Oxides-An Up-to-Date Overview,Materials, 5, 661-683.

[2]. Liqui, Men; Qiying, Chen; Hirokazu, Tada; Hirofumi, Yamada and Kazumi, Matsuushige (1999). Nano Meter Scale CurrentVoltage Characteristics of $\mathrm{C}_{60}$ films. Mol. Cryst. and Liq. Cryst., 337, 519-523.

[3]. Pierson, J.F., Thobor-Keck, A., Billard A. (2003). Cuprite, Paramelaconite and Tenorite films Deposited by Reactive Magnetron Sputtering, Applied surface science, 210, 359-367.

[4]. Richardson T.J., Slack J.L., Rubin M.D. (2000). Electrochromism of Copper Oxide thin films, Proceedings of the 4th International meeting on Electrochromism, Uppsala.

[5]. Ramesh, Chandra; Praveen,Taneja and Pushan,Ayyub(1999). Optical properties of Transparent Nanocrystalline $\mathrm{Cu}_{2} \mathrm{O}$ thin films Synthesized by High Pressure Gas Sputtering,Nano-Structured Materials, 4, 505-512.

[6]. Samarasekara, P. (2010). Characterization of low cost $\mathrm{P}-\mathrm{Cu}_{2} \mathrm{O} / \mathrm{n}-\mathrm{CuO}$ junction, GESJ: Physics, 4(2)

[7]. Pathan, H. M andLokhande C. D. (2004). Deposition of Metal Chalcogenide Thin Films by Successive Ionic Layer Adsorption and Reaction (SILAR) method, Bull. Mater. Sci., 27(2), 85-111.

[8]. ParthaMitra, (2010). Preparation of Coppper Oxide thin films by SILAR and their characterization, Journal of Physical Sciences, $14,235-240$.

[9]. Mohd, R. J., Mohd, S. M. S., Nor, L.H., Hee, A. C., (2011). Annealing Effects on the Properties of Copper Oxide Thin Films Prepared by Chemical Deposition, Int.J.Electrochem.Sci.,6,6094-6104. 